\title{
Giant Primary Apocrine Carcinoma of Frontal Region: Clinical Presentation, Surgical Treatment and Review of the Literature
}

Dragana Petrović Popović ( $\square$ draganapetrovicpopovic@gmail.com )

University Clinical Center of Serbia: Univerzitetski klinicki centar Srbije https://orcid.org/0000-0001-

7960-1244

Marijan Novaković

Clinical Center of Serbia: Klinicki centar Srbije

Milan Stojičić

Clinical Center of Serbia: Klinicki centar Srbije

Dimitrije Brašanac

Univerzitet u Beogradu Medicinski fakultet

Mirjana Petrović Elbaz

James J Peters VAMC: James J Peters VA Medical Center

Maja Nikolić-Živanović

Clinical Center of Serbia: Klinicki centar Srbije

\section{Case report}

Keywords: primary cutaneous apocrine carcinoma, diagnosis, surgical treatment, reconstruction

Posted Date: August 17th, 2021

DOl: https://doi.org/10.21203/rs.3.rs-783421/v1

License: (c) (1) This work is licensed under a Creative Commons Attribution 4.0 International License.

Read Full License 


\section{Abstract}

Background: Primary cutaneous apocrine carcinoma (PCAC), a subtype of sweat gland carcinoma, is an extremely rare malignant neoplasm. Distinguishing apocrine carcinoma from breast carcinoma metastasis is difficult even for pathologist. Most arise in regions of high apocrine gland density like axilla, and rarely on the scalp and eyelid, but it's possible to occur elsewhere on the skin. Primary cutaneous apocrine carcinoma of the scalp is a rare malignancy most often reported in the literature as case reports or small case series. Giant form of primary cutaneous apocrine carcinoma in frontal region is not described in literature, to the best of our knowledge. There no established protocols for primary cutaneous apocrine carcinoma treatment.

Case presentation: We report a case giant primary cutaneous apocrine carcinoma localized in frontal region. Definitive diagnosis of primary cutaneous apocrine carcinoma is made by biopsy with microscopic and immunohistochemical analysis. Wide surgical excision and reconstruction with large local transposition flap and split thickness skin grafts for secondary defect were our therapy of choice.

Conclusion: Primary cutaneous apocrine carcinoma is very rare malignancy and giant form in not described yet. Surgical treatment provided the patients with the tumor free status as well satisfactory aesthetical appearances and quality of living.

\section{Background}

Primary cutaneous apocrine carcinomas (PCAS) are rare and incompletely studied neoplasms, mostly arising in axilla, but it's possible to be found elsewhere on the skin (McKee 2020) (1). Giant form of PCAS in frontal region has not been described in literature, to the best of our knowledge. PCAS is almost impossible to distinguish from cutaneous metastasis of breast apocrine carcinoma on histopathological examination alone $(2,3,4)$.

The standard treatment for PCAC is wide surgical resection and reconstruction $(3,5,6)$. There is no clear consensus on management of regional lymph nodes, and the most important predictor of survival in localized disease is lymph node status; therefore, sentinel lymph node biopsy could be considered in management of this disease $(4,5,6)$. The role of adjuvant chemotherapy and radiotherapy is not established.

Primary cutaneous apocrine carcinoma (PCAC) is a rare cutaneous malignancy with the incidence of $0.005-0.017$ per 100,000 patients per year (3). Males and females are equally affected with the peak of presentation in 6 th and 7 th decades of age and the predominance of Caucasian ethnicity $(1,3)$.

Many of these carcinomas are indolent and slowly developing, but some are rapidly progressive. Majority occur in the genital skin and perineum (34.5\%), followed by trunk $(26.4 \%)$, head and neck $(18.3 \%)$ and lower extremities $(13.9 \%)(3,7)$. They present mostly as nodules or masses $2-3 \mathrm{~cm}$ in size, without any additional symptoms and very rarely can be bigger, more than $5 \mathrm{~cm}$ in diameter $(1,8,9)$. Giant form, with 
diameter more than $10 \mathrm{~cm}$ and few centimeters high has not been described in literature, to the best of our knowledge.

\section{Case Presentation}

A 80-year-old man, was referred with giant, bleeding, malodorous, secreting tumor (about $10 \mathrm{~cm}$ in diameter and $7 \mathrm{~cm}$ over than skin level) in the right side of the scalp with another tumor on the right temporal side (about $3 \mathrm{~cm}$ in diameter) of the scalp, and the tumor in left mandibular area. Patient had noticed giant tumor about 4 years before admission, while two other tumors had been present for a year and a half (Fig. 1).

Preoperatively, the patient was examined by the team of plastic surgeon, radiologist, neurologist and cardiologist and adequately prepared for surgery in general endotracheal anesthesia. The laboratory analyses were within normal limits.

Based on the decision by the tumor board in our Institution the patient underwent radical tumor excision followed by soft tissue defect reconstruction. The wide excision was performed for all three tumors with free margins of $2 \mathrm{~cm}$, followed by reconstruction with large local transposition flap and split thickness skin grafts for secondary defect (Fig. 2).

Histopathological analysis showed identical appearance for giant tumor in parietal region and the smaller tumor in temporal area: nodus with eroded surface, infiltrating dermis, subcutaneous fat and muscles, composed of confluent tumor islands with focal small ducts. Large epithelioid cells with intensely eosinophilic cytoplasm, moderate pleomorphism, and up to 17 mitoses per 10 high-power fields (Fig. 3a) were immunohischemically diffusely positive for pan-cytokeratin (AE1/AE3), CK7 and androgen receptor (Fig. 3b), and focally for Gross-cystic-diseasefluid-protein (GCDFP-15) and carcinoembyonic antigen (pCEA). Staining reaction with CK20, p63, mammaglobin, estrogen (ER) and progesteron (PR) receptors, thyroid-transcription factor (TTF-1), and prostate specific antigen (PSA) were all negative. Based on microscopic and immunohistochemical findings a diagnosis of apocrine carcinoma has been made, with the advise for clinical exclusion of possible metastatic lesion, preferentially from the breast and salivary glands. The head and chest $\mathrm{x}$ - ray, and abdomen/pelvis ultrasound revealed no evidence 
of primary tumor, whereas ultrasound of breasts was without suspicious changes. Tumor in the mandibular region was diagnosed as basal cell carcinoma (nodular type).

The case was reviewed at the Soft tissue tumor board and the decision of no adjuvant treatment, with follow-up every three months, and then every six months has been made. The patient had no evidence of recurrence or any local and visceral metastasis during a one year follow-up.

\section{Disccusion}

Primary cutaneous apocrine carcinoma (PCAC) as a subtype of sweat gland tumors is very rare adnexal neoplasm that arises from apocrine glands and it usually occurs in regions with higher density of apocrine glands such as axilla, groin and anogenital regions but can be found in various body sites $(1,3)$. The definitive diagnosis of PCAC is made by biopsy with histopathological and immunohistochemical analysis. Without the identification of in situ component of the skin tumor it could be impossible to distinguish PCAC from metastasis, particularly of breast carcinoma, which should be excluded with breast examination, clinically and using imaging methods $(9,10,11)$. For lesions in other regions with less density of apocrine gland it could be very difficult to make clinical differential diagnosis from more common skin tumors like basal cell or squamous cell carcinoma.

We reviewed the literature to find best surgical options and treatment modalities. PCAC of the scalp is a rare malignancy most often reported in the literature as case reports or small case- series, therefore there are no established protocols for PCAS treatment, especially for the giant form of PCAS $(3,4,5)$. Most authors advised clear margins about $2 \mathrm{~cm}$ in width. There is no clear consensus on management of lymph nodes at risk. Since the most important predictor of survival in localized disease is lymph node status, sentinel lymph node biopsy could be considered in the management of this disease $(6,8,9)$. The role for neoadjuvant or adjuvant chemotherapy, and radiotherapy or isolated limb perfusion, when tumor is localized on the limb, has not been established, as well as for immunological therapy.

\section{Conclusion}

We describe herein giant form of PCAS of scalp in an elderly patient, diagnosed with histopathological examination, imuniohistochemical analysis, and clinical and imaging investigation for exclusion of metastatic tumor. Wide surgical excision and reconstruction with large local transposition flap and split thickness skin grafts for secondary defect were our therapy of choice. The aforementioned surgical treatment provided the patients with the tumor free status as well satisfactory aesthetical appearances and quality of living (Fig. 4).

\section{Declarations}

Ethic approval and consent to participate - This article was planned in compliance with the Patient Rights Directive and ethical rules by considering the principles of the Declaration of Helsinki. Ethic Committee of 
University Clinical Center of Serbia approved the study No 11721/2020.

Consent for publication - Written informed consent was obtained from the patient for publication of this case report and accompanying images. A copy of the written consent is available for review by the Editorin-Chief of this journal

Availability of data and materials - The data used during the current study are available from the corresponding author on reasonable request.

Competing interests - The authors declare that they have no competing interests

Funding - The authors declare that they have no funding.

Authors' contributions - DPP was a major contributor in writing the manuscript and reviewed literature, MN was giving the idea for this manuscript, writing the manuscript and reviewed literature and interpreted the patient data, MS was writing the manuscript and supervise manuscript, DB performed pathohistological examination and immunohistochemical and made definitive diagnose and supervise mnuscript, MPE was writing the manuscript and performed analyses that excluded other tumors and MNŽ reviewed literature. All authors read and approved the final manuscript.

Acknowledgements - Not applicable

\section{References}

1. Robson A, Lazar AJ, Ben Nagi J, Hanby A, Grayson W, Feinmesser M, Granter SR, Seed P, Warneke CL, McKee PH, Calonje E. Primary cutaneous apocrine carcinoma: a clinico-pathologic analysis of 24 cases. Am J Surg Pathol. 2008 May;32(5):682 - 90. doi: 10.1097/PAS.0b013e3181590ba4. PMID: 18347508.

2. Paties C, Taccagni GL, Papotti M, Valente G, Zangrandi A, Aloi F. Apocrine carcinoma of the skin. A clinicopathologic, immunocytochemical, and ultrastructural study. Cancer. 1993 Jan 15;71(2):375 81. doi: 10.1002/1097-0142(19930115)71:2<375::aid-cncr2820710218>3.0.co;2-4. PMID: 7678545.

3. Hollowell KL, Agle SC, Zervos EE, Fitzgerald TL. Cutaneous apocrine adenocarcinoma: defining epidemiology, outcomes, and optimal therapy for a rare neoplasm. J Surg Oncol. $2012 \mathrm{Mar}$ 15;105(4):415-9. doi: 10.1002/jso.22023. Epub 2011 Sep 12. PMID: 21913192.

4. Kim HK, Chung KI, Park BY, Bae TH, Kim WS, Lee TJ. Primary apocrine carcinoma of scalp: report of primary scalp cutaneous apocrine carcinoma indistinguishable from cutaneous metastasis of breast carcinoma. J Plast Reconstr Aesthet Surg. 2012 Mar;65(3):e67-70. doi: 10.1016/j.bjps.2011.11.001. Epub 2011 Nov 27. PMID: 22122891.

5. Seo KJ, Kim JJ. Primary cutaneous apocrine gland carcinoma from areolar tissue in a male patient with gynecomastia: a case report. J Cardiothorac Surg. 2015 Sep 8;10:111. doi: 10.1186/s13019- 
015-0319-5. PMID: 26349536; PMCID: PMC4562102.

6. Chamberlain RS, Huber K, White JC, Travaglino-Parda R. Apocrine gland carcinoma of the axilla: review of the literature and recommendations for treatment. Am J Clin Oncol. 1999 Apr;22(2):131-5. doi: 10.1097/00000421-199904000-00005. PMID: 10199445.

7. Yildirim S, Aköz T, Akan M, Ege GA. De novo malignant eccrine spiradenoma with an interesting and unusual location. Dermatol Surg. 2001 Apr;27(4):417 - 20. doi: 10.1046/j.1524-4725.2001.00027.x. PMID: 11298720.

8. Roy S, Shafi NQ, Rose MG. Locally recurrent and metastatic apocrine-gland carcinoma in an elderly man. Nat Clin Pract Oncol. 2007 Jan;4(1):56 - 9. doi: 10.1038/ncponc0694. PMID: 17183356.

9. Obaidat NA, Alsaad KO, Ghazarian D. Skin adnexal neoplasms-part 2: an approach to tumours of cutaneous sweat glands. J Clin Pathol. 2007 Feb;60(2):145-59. doi:10.1136/jcp.2006.041608. Epub 2006 Aug 1. PMID: 16882695; PMCID: PMC1860616.

10. Zelger BG, Stelzmueller I, Dunst KM, Zelger B. Solid apocrine carcinoma of the skin: report of a rare adnexal neoplasm mimicking lobular breast carcinoma. J Cutan Pathol. 2008 Mar;35(3):332-6. doi: 10.1111/j.1600-0560.2007.00804.x. PMID: 18251751.

11. Loh SH, Oh YJ, Lew BL, Sim WY. Primary Cutaneous Apocrine Carcinoma. Ann Dermatol. 2016 Oct;28(5):669-70. doi:10.5021/ad.2016.28.5.669. Epub 2016 Sep 30. PMID: 27746659; PMCID: PMC5064209.

\section{Figures}

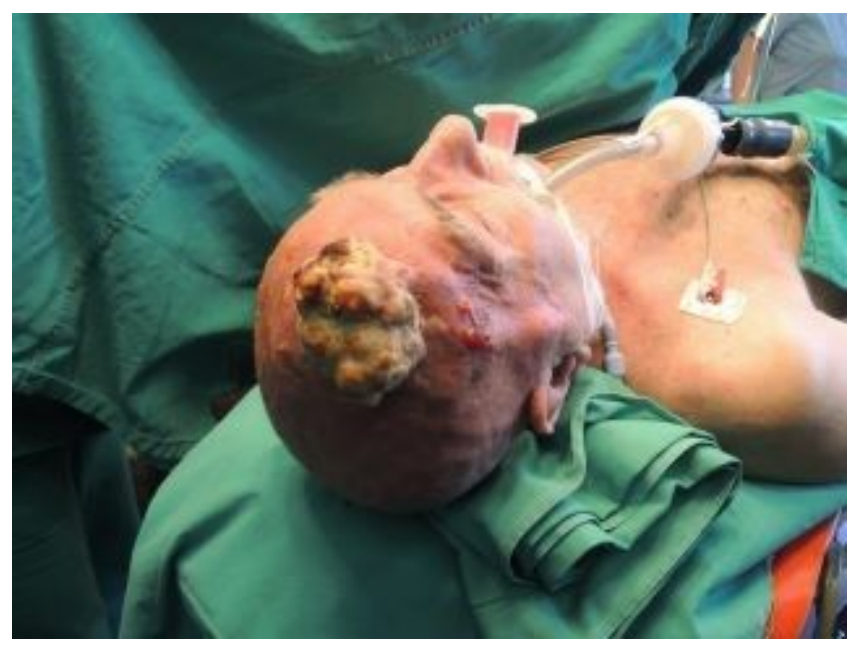

\section{Figure 1}

Preoprative view - giant tumor in frontal region is PCAC. 


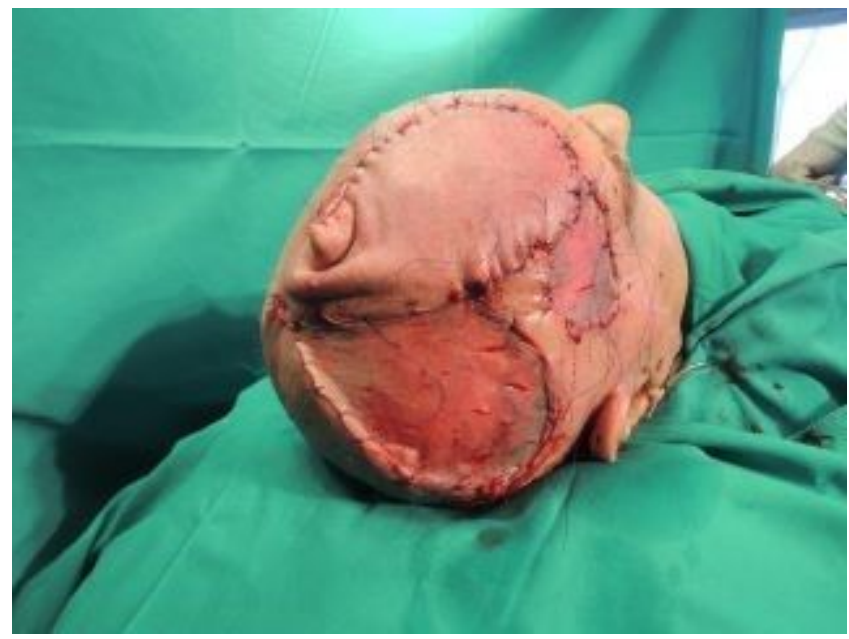

Figure 2

Postoperative view - wide excision and reconstruction with large local transposition flap and split thickness skin grafts for secondary defect.
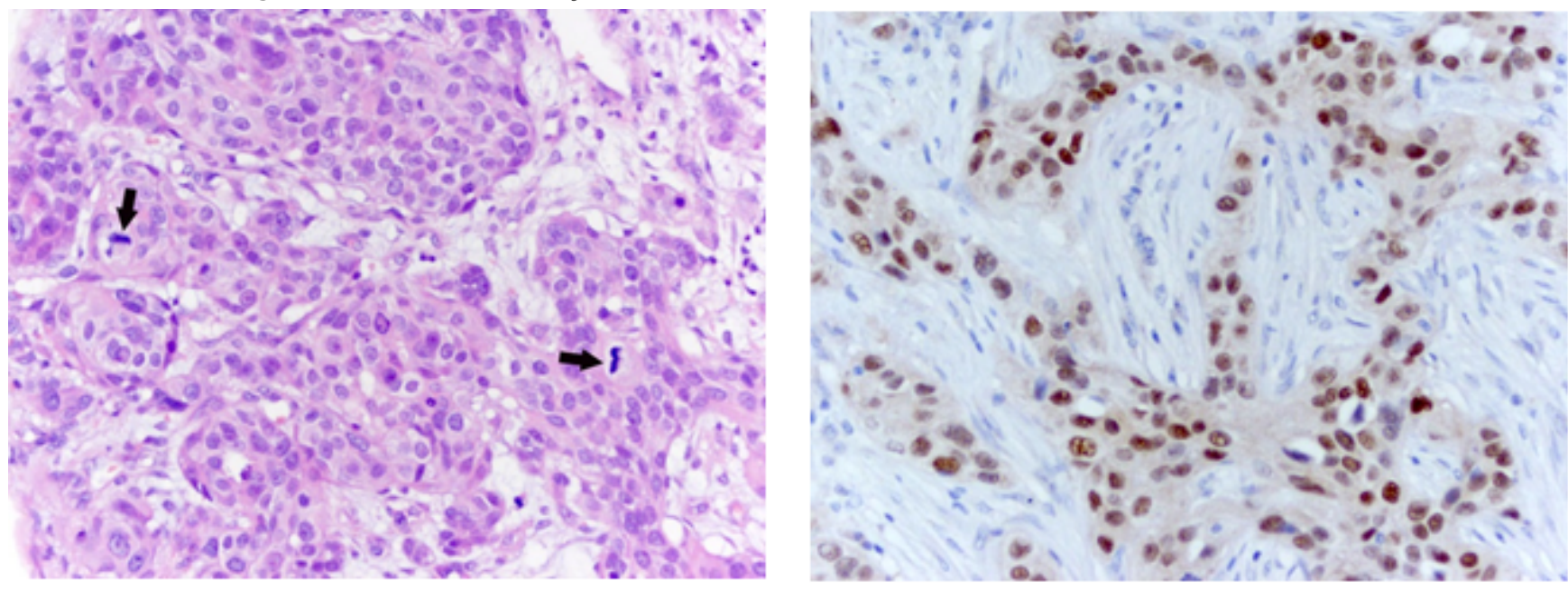

A

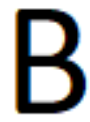

Figure 3

Apocrine carcinoma of the scalp, microscopic presentation (a) with predominantly solid growth pattern and scattered mitoses (arrows) (hematoxylin\&amp;eosin, original magnification 200x): immunohistochemical staining (b) showing expression of androgen receptors (200x). 


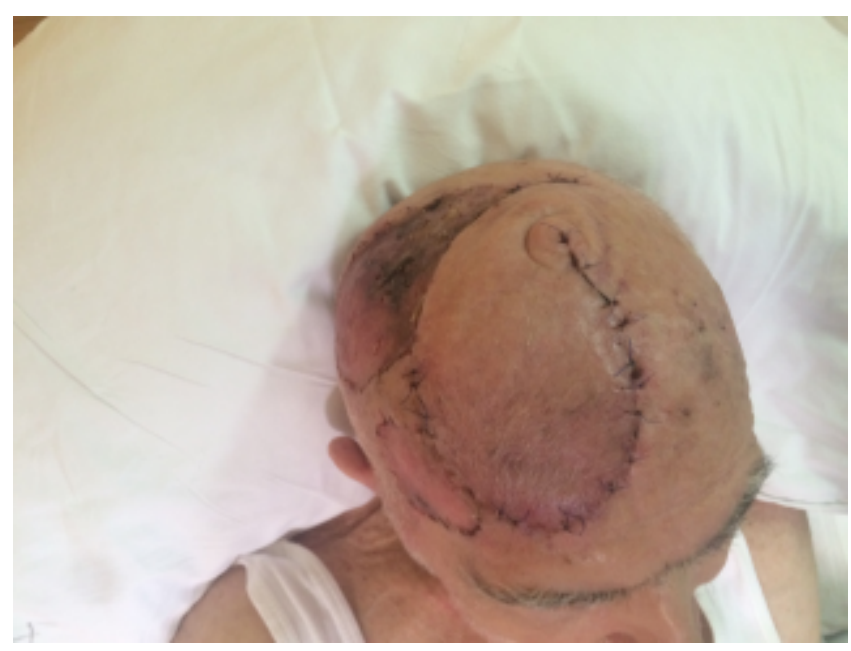

Figure 4

One month after surgery - very satisfactory aesthetical appearances. 